\title{
Validation of the Kazakh-language version of the World Health Organization's WHOQOL-BREF questionnaire on the quality of life among the elderly population of Aktobe city
}

\author{
Nurgul Abenova, Akbayan Imanbayeva, Bibigul Karimsakova, Inkara Essengalyeva \\ No1 Department of General medical practice, West Kazakhstan Marat Ospanov Medical University, Aktobe, Kazakhstan
}

Received: 2021-03-30.

Accepted: 2021-09-13

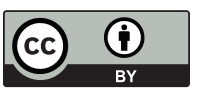

This work is licensed under a Creative Commons Attribution 4.0 International License
J Clin Med Kaz 2021; 18(5):35-43

Corresponding author:

Nurgul Abenova.

E-mail: nurgul_abenova@mail.ru;

ORCID: 0000-0003-0395-9025.

\begin{abstract}
Introduction: In Kazakhstan, as the phenomenon of population aging becomes more and more relevant, an increasing number of researchers in the field of medicine are studying health-related problems that arise at this age. During these studies, many scientists are wondering: how to accurately measure the quality of life of older people? In our country, the most used tools for conducting this assessment are the SF-36 questionnaire, while the widely used worldwide tools WHOQOL-10O and its short version WHOQOL-BREF are rarely evaluated and used in the Republic of Kazakhstan. Thus, the aim of this study was to determine the psychometric properties of the Kazakh-language version of the World Health Organization's Short Quality of Life Questionnaire (WHOQOL-BREF) in a pilot study.

Material and methods: The WHOQOL-BREF questionnaire was subjected to translation procedures according to the instructions of WHOQOL (WHO) and a pilot study was conducted in a group of elderly respondents (>60 years old) living in the city of Aktobe. The WHOQOLBREF questionnaire consists of 26 questions, which are divided into 4 areas (physical health, emotional health, social factors, environment). The reliability and validity of the questionnaire was evaluated with the determination of the Alpha-Cronbach's index, as well as the assessment of the intra-class correlation (ICC). The statistical significance was set at 0.05. The software package SPSS v. 10.0 was used for the analysis.

Results: The average age of the participants was $67.3 \pm 5.03$ years, and the overall WHOQOL-BREF score was $76.02 \pm 11.86$. Overall, $60 \%$ of the participants were women. The alpha values for each of the spheres and the overall index (>0.70) and the overall correlation of the elements were satisfactory. The confirmatory analysis of the intra-class correlation showed high ICC values (more than 0.74) for each of the spheres.
\end{abstract}

Conclusion: The psychometric properties of the Kazakh version of WHOQOL-BREF were acceptable.

Key words: elderly people, cultural adaptation, reliability and validity, quality of life

\section{Introduction}

According to the United Nations Population Fund for Demography, Development and Gender (UNFPA), the demographic situation in Kazakhstan is characterized by an increase in the proportion of older people in the age structure of the country's population. At the beginning of 2019 , the share of the population aged over 60 years was $11.6 \%$ of the total population of the Kazakhstan, and those aged 65 years and older $-7.5 \%$ [1]. The country is in the initial stage of demographic aging [2]. At the same time, in half of the country's regions, the $7 \%$ threshold characteristic of an aging nation has already been significantly overcome. According to UNFPA projections, the share of older persons aged 65 and over, at $7.3 \%$, will continue to grow by 2050 and will almost double [3]. Although today Kazakhstan is a relatively young nation, it is necessary to think about the trends and consequences generated by the aging of the population in advance. 
Older people are more likely to suffer from multiple diseases due to reduced physical and mental functions. Loneliness, sexual dysfunction, and chronic metabolic disorders are some of the causes that can lead to emotional disorders [4]. These problems can reduce the quality of life of older people.

According to WHO, quality of life is defined as a person's perception of their position in life in the context of the culture and value systems in which they live, and in relation to their goals, expectations, standards and challenges [5]. In addition, quality of life is described as well-being resulting from a combination of physical, functional, emotional, and social factors [6].

Poor economic, cultural, educational, and health conditions, as well as inadequate social interaction, can lead to a decline in the quality of life of older people [7-9]. Chronic diseases, such as diabetes mellitus, coronary heart disease, osteoporosis and cerebrovascular diseases are the most common diseases in the elderly. These disorders, which cause medical, social and psychological problems, can reduce the physical function and quality of life of older people in society [10-13].

In Kazakhstan, there are not many studies devoted to the study of the quality of life in the elderly population. The few studies conducted in the cities of central significance (Almaty and Nur-Sultan) were conducted mainly using the common SF-36 questionnaire [14], while the WHO questionnaire was not used to study the quality of life. The WHO Quality of Life Questionnaire (WHOQL-100) is one of the most appropriate tools, which is acceptable for use in different cultures and is widely used in various epidemiological studies [15]. The development and testing of the Russian version of the WHOQOL-100 questionnaire was carried out on the basis of the department of psychoprophylaxis and outpatient psychiatry of the St. Petersburg Psychoneurological Institute named after V.M. Behterev, which has the status of a WHO regional research center [16], where it is tested for quality of life. The Russian-language version of the questionnaire is officially recognized by the WHO and is available for general use on the developer's website. The short version of this questionnaire, consisting of 26 questions, has proven its reliability, validity and sensitivity by numerous studies in 19 countries, including Russia. However, there is currently no version available in Kazakh, which is the official language in Kazakhstan. Thus, the aim of this study was to adapt a short version of the WHOQOL questionnaire (WHOQOLBREF) for use among the Kazakh-speaking population and to assess its reliability and reliability.

\section{Materials and methods}

The questionnaires developed for the first time are subject to the mandatory validation procedure, as well as when adapting the already validated questionnaires to the linguistic and cultural characteristics of a particular country. Validation in this case consists of the following stages: translation, preliminary testing, assessment of reliability and, validity assessment. This study was approved by the local bioethical committee at the NJSC "West Kazakhstan Marat Ospanov Medical University". All participants signed an informed written consent prior to the survey.

Our questionnaire validation process consisted of the following stages: Preparation, Translation, Preliminary testing, Assessment of the reliability of the questionnaire

\section{Preparation.}

Prior to conducting the study using the WHOQOLBREF questionnaire, an agreement was signed with a group of WHO researchers and appropriate translation instructions were received.

\section{Translation.}

At 1-st step, the original version of the questionnaire was translated into Kazakh. The translation was carried out by two professional translators, native speakers, independently of each other. The translators were not medical specialists, but certified English language specialists. During the translation process, each of the translators made a direct translation of the original WHOQOL-BREF questionnaire, instructions, and answer options. After comparing both versions of the translation and matching, a combined verified version, Version 1, was created.

At step 2, the verified Version 1 was translated into the original (English) language. The translation was carried out by professional translator, a native English speaker. One of the conditions for the reverse translation was that the translator did not have access to the original version of the questionnaire. These two new versions were compared and served as the basis for a consensus version of the English translation of the questionnaire. This version, Version 2, in the Kazakh language was grammatically and semantically acceptable.

At the 3rd step of creating the Kazakh-language version, a pilot test of the created Version 2 was conducted on patients who were native speakers of the Kazakh language. This step is necessary in order to determine the acceptability of the translation (instructions, questions and answers). After the translation from the original, two main aspects were checked: the equivalence of points and answer options. There were 30 respondents took part in the testing. All the subjects were native speakers of the Kazakh language. The questionnaire was completed by each respondent independently of each other, and if difficulties arose, the subject turned directly to the interviewer. At the end of the survey, the interviewer also asked if the interviewee had any problems, understanding the questionnaire and completing it. During the survey, the wording of the questions and answer options was adjusted based on the wishes of the respondents. There were no changes due to the Version 2 survey. There were $85 \%$ of the respondents said that they understood the content and everything is clear from a cultural point of view. Thus, Version 2 of translated questionnaire was accepted as the final version in the Kazakh language.

3. Preliminary testing.

To confirm its applicability in everyday practice, the Kazakh version of the WHOQOL-BREF questionnaire was tested in two stages on 30 native-speaking patients. The criteria for inclusion in the pilot study were:

- elderly age (60-74 years);

- fluency in the Kazakh language;

- absence of concomitant severe somatic or mental illness.

4. Assessment of the reliability of the questionnaire.

Assessment of the reliability of the questionnaire was carried out with the study of such indicators as:

- Internal consistency: Cronbach's Alpha coefficient alpha $(\alpha)$ was used to calculate internal consistency for each area of the WHOQOL-BREF questionnaire. If the values of Cronbach's $\alpha$ coefficient were more than 0.7 , then they testified to sufficient internal consistency (Cronbach L. Coefficient alpha and the internal structure of tests. Psychometrica 1951;16)

- Reliability stability, characterized by the stability of the results over time, was carried out using the test-retest method in a subgroup of 10 participants who completed the questionnaire twice within 10 days. The results of the two tests were compared by calculating the Pearson correlation coefficient. At the same time, a statistically significant correlation coefficient $>0.7$ testified to the sufficient reliability of the tested questionnaire. 


\section{Questionnaire}

This WHOQOL-BREF questionnaire is characterized by both brevity and ease of use, as well as multi-dimensionality. It allows you to get an assessment of the quality of life of the respondent as a whole, as well as private assessments for individual domains. It is applicable to a wide range of contingents, covering the full range of functions, disabilities and distresses that relate to quality of life. WHOQOL-BREF is a 26-point questionnaire covering 4 aspects of quality of life (psychological -6 questions, physical -7 , social -3 , and environmental -8 ). The score for each question has answer categories from 1 to 5 , with a high score indicating a high quality of life, with the exception of three questions regarding pain and discomfort, the need for treatment, and negative emotions. The physical health measurement includes 7 items (mobility, daily activity, pain, sleep, functional ability, and energy). The psychological field evaluates negative thinking, self-esteem, positive attitude, self-esteem, mindset, learning ability, memory, consolidation, religion, and mental state. Issues such as social support, sexual life, and personal relationships fall within the realm of social relations. The field of environmental health includes questions about financial assets, safety, health and social services, living in a natural environment, learning experiences, relaxation, and the environment such as air, noise, pollution, and transportation [17]. The sum of points in each area demonstrates a person's personal perception of the quality of life. All area scores were scaled positively (a higher score indicates a higher quality of life). The conversion of the raw indicator was done using the WHO developer's spreadsheet given to convert the raw indicator to converted scores. A score above the average (50\%) of the total score is classified as an acceptable level of quality of life.

Statistical data processing was performed using the STATISTICA 10 application software package for Windows (StatSoft, USA).

\section{Results}

The pilot study involved 30 patients, all of whom were randomly selected from the list of the attached elderly population from Aktobe city. There were no obstacles either in the questions or in the answers section of the questionnaire. One WHOQOLBREF questionnaire took between 9 and 17 minutes to complete (median $=11$ minutes). The socio-demographic characteristics of the respondents who took part in the study are presented in - Table 1.

\section{Table 1 Socio-demographic characteristics of} respondents $(n=30)$

\begin{tabular}{|l|l|l|}
\hline Characteristics & Number of patients & $\%$ \\
\hline Age (year) & & \\
\hline Middle age & $67,3 \pm 5,03$ & - \\
\hline Age ranging & $60-74$ & - \\
\hline Gender & & \\
\hline Male & 12 & 40 \\
\hline Female & 18 & 60 \\
\hline Education & & \\
\hline Secondary education & 3 & 10 \\
\hline $\begin{array}{l}\text { Secondary special } \\
\text { education }\end{array}$ & 12 & 40 \\
\hline Higher education & 15 & 50 \\
\hline Marital status & & 70 \\
\hline Married & 21 & 10 \\
\hline Single & 3 & 20 \\
\hline Widow / widower & 6 &
\end{tabular}

Among the respondents there were 18 women and 12 men. The age of the respondents ranged from 60 to 74 years, while the average age of the patients was $67.3( \pm 5.03)$ years. According to the requirements for the translation procedure, all respondents were native speakers of the Kazakh language. As for marital status: $21(70 \%)$ of the respondents were married, $3(10 \%)$ answered "single", 6 (15\%) - "widow/widower". 15 (50\%) of the respondents had higher education, $12(40 \%)$ - secondary vocational education, and $3(10 \%)$ - secondary education. The survey was conducted by a trained medical professional through a personal interview. To ensure confidentiality, interviews were conducted in a separate room or room separated from other family members or visitors to the clinic.

To assess the reliability of retesting, every 3rd participant was selected from the study, and the same questionnaire was asked to the same member twice, 2 weeks apart.

\section{Reliability}

The WHOQOL-BREF questionnaire in Kazakh as a whole and its domain separately had a Cronbach's Alpha coefficient above the boundary value of the indicator $\alpha \geq 0.70$, which indicates an acceptable level of internal consistency of the instrument scales. Thus, the total Cronbach's Alpha index for the Kazakh-language instrument was equal to $\alpha=0,73$. In the questionnaire, the highest value of the coefficient was for the domain of physical health $(\alpha=0,78)$, in second place - the domain of psychological health with the indicator $\alpha=0,72$. The lowest value of the coefficient was in the domain of social relations and was equal to the value of $\alpha=0,70$ (Table 2).

As already described in the methods of this study, the assessment of the reliability of the questionnaire in terms of the stability of the results was carried out by re-testing patients and calculating the Pearson correlation coefficient. The time between the initial test and the re-test ( $\mathrm{t}$ ) was an average of 10 days. The values of the Pearson correlation coefficient (r), when studying the reliability of the instrument over time by conducting a retest, varied from $r=0,70$ to $r=0,78$. This indicator was the lowest for the social relationship domain. The correlation coefficient between the responses of the respondents in the initial and repeated testing for the main questionnaire was $r=0,74$. In each of the 4 domains, the elements are significantly correlated at a level of less than $p<0,05$.

After the pilot study, the next stage of our work was to study the quality of life of the Kazakh-speaking elderly population according to the age-sex characteristics of the city of Aktobe, using the Kazakh-language version of the WHO quality of life questionnaire. In the city of Aktobe, according to the census of 01.01 .2020 , a population of 500757 people was registered, among them the elderly population from 60 to 74 years old -42 980 people, of which 16989 were men, 25991 were women.

The sample size of 437 older people assigned to the city's primary health care facility was obtained with a 5\% margin of error, 95\% confidence interval, $50 \%$ prevalence, and $20 \%$ wastage loss.

56 people refused the study, so the analysis was limited to 381 respondents, while the amount of losses was $12.8 \%$. The multistage cluster sampling method was used and carried out in all polyclinics of the city from November 2019 to March 2020. Guests and temporary residents were excluded from the study. In the city of Aktobe, there are 7 polyclinics that monitor the attached population. In the first step, we randomly selected outpatient clinics using a simple random sampling technique. In the next step, we again selected the number of households in this 


\begin{tabular}{|l|l|l|l|}
\hline Domains & Question No & Average score (SD) \\
\hline $\mathrm{n}=30$ & Alpha coefficients $\mathrm{n}=30$ & & \\
\hline Physical health & $3,4,10,15,16,17,18$ & $25.18(4.26)$ & 0,78 \\
\hline Psychological health & $5,6,7,11,19,26$ & $22.18(3.56)$ & 0,72 \\
\hline Social relationships & $20,21,22$ & $11.64(1.97)$ & 0.70 \\
\hline Environmental health & $8,9,12,13,14,23,24,25$ & $22.75(4.73)$ & $76,02(11,86)$ \\
\hline The questionnaire as a whole & $1-26$ & 0.71 \\
\hline
\end{tabular}

Table 3

Time stability of the WHOQOL-BREF questionnaire in Kazakh language

\begin{tabular}{|l|l|l|l|l|}
\hline Domains & Question No & \multicolumn{3}{l|}{ Test-retest (n=10) } \\
\hline & & $\mathrm{r}$ & $\mathrm{p}$ & $\mathrm{t}$ \\
\hline Physical health & $\begin{array}{l}3,4,10,15,16, \\
17,18\end{array}$ & 0,71 & 0,03 & 10 \\
\hline Psychological health & $5,6,7,11,19,26$ & 0,72 & 0,02 & 10 \\
\hline Social relationship & $20,21,22$ & 0,70 & 0,005 & 10 \\
\hline $\begin{array}{l}\text { Environmental } \\
\text { health }\end{array}$ & $\begin{array}{l}8,9,12,13,14,23, \\
24,25\end{array}$ & 0,78 & 0,01 & 10 \\
\hline $\begin{array}{l}\text { The questionnaire } \\
\text { as a whole }\end{array}$ & $1-26$ & 0,74 & 0,05 & 10 \\
\hline
\end{tabular}

selected plot using a random sampling method. In each district, the number of households was proportional to the population in the district.

The survey was conducted by a trained healthcare professional through a personal interview. To ensure confidentiality, interviews were conducted in a separate room or space separated from other family members.

The characteristics of participants in the age range 60-74 years are presented in Table 4.

The average age of 381 elderly people was within 66.5 (4.23) years. Of these, $52.2 \%$ - 199 women and 182 men $(47.8 \%)$. There was no significant difference in the sex ratio in the study $(\mathrm{P}=0.461) .85(22.3 \%)$ had higher education, 142 $(37.3 \%)$ had secondary education, and 154 participants $(40.4 \%)$ had primary education. The family status of the respondents: family (married) amounted to 182 (47.8\%), single $12(3.1 \%)$, divorced 31 (8.1\%), widowed $156(41 \%)$.

As for the assessment of quality of life indicators (in the range from 1 to 5), the results showed that the overall indicators of the quality of life in participants of both sexes were at an acceptable level and amounted to 85.2 (10.6) and 86.9 (10.3), respectively. The average scores by area and the overall assessment of the quality of life, depending on gender, are shown in Table 5.

As can be seen from the data on the quality of life indicators, there were no significant differences in the general perception of the quality of life among men and women (Table 6). There were no differences in domains in terms of assessing the quality of life in the domains of physical and psychological health, as well as in the domain of social relations. With the exception of the environment and financial resources, where the values of the quality of life in women were statistically significantly higher than in men $(p=0.006)$. It can be assumed
Table $4 \quad$ Characteristics of study participants

\begin{tabular}{|l|l|}
\hline Characteristic & $\mathrm{n}(\%)$ \\
\hline Average age (SD) & $66,5(4,23)$ \\
\hline Gender & \\
\hline Men & $182(47,8 \%)$. \\
\hline Women & $199(52,2)$ \\
\hline Marital status & \\
\hline Married & $182(47,8 \%)$ \\
\hline Divorced & $31(8,1 \%)$ \\
\hline Lonely & $12(3,1 \%)$ \\
\hline Widowed & $156(41,0 \%)$ \\
\hline Education & \\
\hline Higher & $85(22,3 \%)$ \\
\hline Secondary professional & $142(37,3 \%)$ \\
\hline Primary (school) & $154(40,4 \%)$ \\
\hline
\end{tabular}

that this fact is due to the fact that women at this age feel more mobile and free in movement due to the fact that children have gained independence, there is a stable pension provision, more free time that can be used for their own purposes. Also, children in many cases provide financial support to mothers, which is closely related to the mentality and upbringing in Kazakh society. Whereas men note lower indicators of the quality of life in this area. Perhaps this is due to an increase in the number of chronic diseases and a decrease in income due to retirement, which is one of the key factors in the perception of the quality of life.

As for the assessment of the overall quality of life of the urban elderly population, it was higher than the average and amounted to $85.0( \pm 10.5)$ points. The fairly high quality of life among the elderly in the city is possibly due to the limitation of our sample; we did not include elderly patients with severe somatic and psychological illnesses who could not answer the questionnaire in the study. Perhaps people who completed the survey were more satisfied than average with their quality of life.

When assessing the quality of life by age, all respondents were divided according to age into three categories: I - from 60 to 64 years old, II - 65-69 years old, and III from 70-74 years old. Quality of life indicators depending on age are presented in Table 7.

When assessing the quality of life for three age categories, the following data were obtained: higher age was significantly associated with a lower quality of life indicator. When assessing the general indicator of the quality of life, statistically significant differences were revealed between the I and III $(5.04, p=0.0000)$ age categories, between the II and III age categories (2.75, $\mathrm{p}=0.017$ ), which indicates a deterioration in the quality of life of elderly patients with age. 


\begin{tabular}{|c|c|c|c|}
\hline \multirow[t]{2}{*}{ Domains } & \multicolumn{3}{|l|}{ Elderly people } \\
\hline & $\begin{array}{l}\text { Men } \\
\mathrm{n}=182\end{array}$ & $\begin{array}{l}\text { Women } \\
\mathrm{n}=199\end{array}$ & $\begin{array}{l}\text { All } \\
\mathrm{n}=381\end{array}$ \\
\hline \multicolumn{4}{|l|}{ 1. Physical health } \\
\hline Daily activities & $3.49(0.81)$ & $3.42(0.83)$ & $3.41(0.83)$ \\
\hline Dependence on drugs and excipients & $3.10(1.11)$ & $3.02(1.13)$ & $3.05(1.12)$ \\
\hline Energy and fatigue & $3.50(0.92)$ & $3.61(0.94)$ & $3.57(0.94)$ \\
\hline Mobility & $3.48(1,01)$ & $3.6(1.13)$ & $3.55(1.06)$ \\
\hline Pain and discomfort & $2.81(1.02)$ & $2.95(1.05)$ & $2.90(1.05)$ \\
\hline Sleep and rest & $3.38(1.2)$ & $3.18(1.20)$ & $3.28(1.20)$ \\
\hline Performance & $3.42(0.84)$ & $3.38(0.87)$ & $3.40(0.86)$ \\
\hline Total (7-35) & $23.1(2.61)$ & $23,4(2.51)$ & $23.3(2.56)$ \\
\hline \multicolumn{4}{|l|}{ 2. Psychological health } \\
\hline Negative feelings & $3.54(1.30)$ & $3.55(1.18)$ & $3.55(1.24)$ \\
\hline Positive feelings & $3.42(0.83)$ & $3.41(0.82)$ & $3.42(0.80)$ \\
\hline Self-esteem & $3.34(0.91)$ & $3.52(0.80)$ & $3.44(0.85)$ \\
\hline Spirituality / Religion / & $3.72(0.86)$ & $3.58(0.84)$ & $3.66(0.83)$ \\
\hline Personal beliefs & $3.42(0.78)$ & $3.34(0.87)$ & $3.38(0.82)$ \\
\hline Thinking, learning, memory and concentration & $3.41(0.92)$ & $3.59(0.84)$ & $3.51(0.90)$ \\
\hline Total (6-30) & $22.2(2.97)$ & $22.3(2.81)$ & $22,2(2.89)$ \\
\hline \multicolumn{4}{|l|}{ 3. Social relationships } \\
\hline Personal relationships & $3.96(0.77)$ & $3.67(0.93)$ & $3.83(0.87)$ \\
\hline Social support & $2.98(1.15)$ & $3.02(1.13)$ & $3.00(1.13)$ \\
\hline Sexual activity & $3.67(0.89)$ & $3.32(1.00)$ & $3.50(0.96)$ \\
\hline Total (3-15) & $10.2(2.38)$ & $10.0(2.36)$ & $9.87(2.37)$ \\
\hline \multicolumn{4}{|l|}{ 4. Environment Financial resources } \\
\hline Freedom, physical safety and security & $3.44(0.88)$ & $3.54(0.85)$ & $3.50(0.86)$ \\
\hline Healthcare and Social Assistance: Availability and Quality & $3.59(0.81)$ & $3.76(0.92)$ & $3.68(0.87)$ \\
\hline Financial support & $3.25(1.13)$ & $3.31(1.14)$ & $3.29(1.08)$ \\
\hline Home environment & $3.49(0.91)$ & $3.53(0.91)$ & $3.51(0.91)$ \\
\hline Opportunities for new information and skills & $3.62(0.96)$ & $3.56(0.99)$ & $3.59(.0 .91)$ \\
\hline Participation and recreational / leisure opportunities & $3.68(0.90)$ & $3.72(0.89)$ & $3.70(0.90)$ \\
\hline Total 8-40 & $29,5(4,47)$ & $30,1(4.57)$ & $30.2(4.56)$ \\
\hline TOTAL by domains & $85.2(10.6)$ & $86.9(10.3)$ & $85.0(10,5)$ \\
\hline
\end{tabular}

Table 6 Comparison of qualitative data by domains of the questionnaire depending on gender

\begin{tabular}{|c|c|c|c|}
\hline Domains & Men $(n=182)$ & Women $(n=199)$ & *p \\
\hline Physical health & $23.1(2.61)$ & $23,4(2.51)$ & 0,366 \\
\hline Psychological health & $22.2(2.97)$ & $22.3(2.81)$ & 0,121 \\
\hline Social relationships & $10.2(2.38)$ & $10.0(2.36)$ & 0,290 \\
\hline Environment and financial resources & $29,5(4,47)$ & $30,1(4.57)$ & $0,006^{* *}$ \\
\hline The overall value of quality of life & $85.2(10.6)$ & $86.9(10.3)$ & 0,119 \\
\hline
\end{tabular}

In the field of physical health, there are statistically significant differences in age categories I and III (4.42, $\mathrm{p}=0.001)$, II and III $(2.55, \mathrm{p}=0.03)$. Whereas there were no statistically significant differences in age categories I and II (1.91, $\mathrm{p}=0.16)$. At the same time, higher age correlated negatively with the area of physical health.

According to the indicators of psychological health and self-perception (domain 2), significant differences were revealed when comparing groups I and II $(2.98, \mathrm{p}=0.008)$, as well as groups I and III $(4.18, p=0.000)$. Significant differences in psychological health between II and III age group was not identified (1.27, $\mathrm{p}=0.6)$.

When assessing the indicators of the domain of social relations, statistically significant differences were revealed in indicators of the I and III age groups $(3.87, p=0.0003)$, which indicates a deterioration in the domain of social relations with increasing age.
When assessing the quality of life indicators in domain 4 (environment and financial resources), statistically significant differences were revealed in I and III (4.62, $\mathrm{p}=0.00001)$, II and III $(3.37, \mathrm{p}=0.002)$ age groups, which also indicates deterioration in the quality of life associated with financial support and the attitude of the environment depending on age.

When assessing the quality of life with and without background diseases, statistically significant differences were observed in the quality of life in respondents with a history of cardiovascular diseases, disorders in the sense organs and comorbid conditions ( 2 or more diseases in the history) $(\mathrm{p}<0.05)$. However, these differences were not so obvious in respondents with diseases of the musculoskeletal system and diseases of the gastrointestinal tract. Unambiguously, the presence of one or another chronic disease leads to a significant decrease in the quality of life in all areas, which is confirmed in our study. Respondents with certain chronic diseases had statistically 


\begin{tabular}{|c|c|c|c|c|c|}
\hline \multirow[t]{2}{*}{$\begin{array}{l}\text { Quality of life metrics } \\
\text { by domain }\end{array}$} & \multirow[t]{2}{*}{$\begin{array}{l}\text { I age group } \\
\mathrm{N}=135\end{array}$} & \multirow[t]{2}{*}{$\begin{array}{l}\text { II age group } \\
\mathrm{N}=130\end{array}$} & \multirow[t]{2}{*}{$\begin{array}{l}\text { III age group } \\
\mathrm{N}=116\end{array}$} & Kruskal - Wallis test & \\
\hline & & & & $r$ & $\mathrm{p}$ \\
\hline \multirow[t]{2}{*}{ Physical health } & $23.9(2.53)$ & & $22.56(2.58)$ & 4.42 & $0.001^{* *}$ \\
\hline & & $23.3(2.43)$ & $22.56(2.58)$ & 2.55 & $0.03^{*}$ \\
\hline \multirow[t]{2}{*}{ Psychological health } & $23.2(2.79)$ & $22.3(2.67)$ & & 2.98 & $0.008^{* *}$ \\
\hline & $23.2(2.79)$ & & $21.8(3.06)$ & 4.18 & $0.000^{* * *}$ \\
\hline Social relationships & $10.7(2.20)$ & $10.0(2.31)$ & $9.51(2.47)$ & 3.87 & $0.000^{* * *}$ \\
\hline \multirow{2}{*}{\begin{tabular}{|l} 
Environment and \\
financial resources
\end{tabular}} & $31.1(4.40)$ & & $28.7(4.44)$ & 4,62 & $0.000^{* * *}$ \\
\hline & & $30.4(4.51)$ & $28.7(4.44)$ & 3.37 & $0,002^{* *}$ \\
\hline \multirow{2}{*}{$\begin{array}{l}\text { The overall value of } \\
\text { quality of life }\end{array}$} & $89.0(9.89)$ & & $82.6(10.73)$ & 5.04 & $0,000^{* * *}$ \\
\hline & & $86.2(10.05)$ & $82.6(10.73)$ & 2.75 & $0.017^{*}$ \\
\hline
\end{tabular}

\section{Table 8} Relationship between Overall Quality of Life and Disease

\begin{tabular}{|c|c|c|c|}
\hline Indicators & Average quality of life (SD) & $x^{2}$ & $\mathrm{P}$ \\
\hline Cardiovascular diseases & $81.1(10.8)$ & 6.96 & $0.008^{* *}$ \\
\hline Respiratory diseases & $84.5(10.9)$ & 5.33 & $0.005^{* *}$ \\
\hline Diseases of the gastrointestinal tract & $83.5(11.4)$ & 0.10 & 0.74 \\
\hline Hearing impairment & $87.3(9.97)$ & 6.67 & $0.001^{* * *}$ \\
\hline \begin{tabular}{|l|} 
Visual impairment \\
\end{tabular} & $86.0(10.4)$ & 5.14 & $0.001^{* * *}$ \\
\hline $\begin{array}{l}\text { Diseases of the musculoskeletal } \\
\text { system }\end{array}$ & $81.4(11.5)$ & 3.45 & 0.06 \\
\hline Diseases of the nervous system & $88.4(9.51)$ & 15.06 & $0.001^{* * *}$ \\
\hline
\end{tabular}

\section{Table 9 The relationship between educational attainment and quality of life}

\begin{tabular}{|c|c|c|c|c|c|}
\hline \multirow{2}{*}{\begin{tabular}{|l} 
Quality of life \\
indicators
\end{tabular}} & \multirow{2}{*}{$\begin{array}{l}\text { Higher education } \\
\mathrm{N}=85\end{array}$} & \multirow{2}{*}{\begin{tabular}{|l} 
Secondary education \\
$\mathrm{N}=142$
\end{tabular}} & \multirow{2}{*}{$\begin{array}{l}\text { Primary education } \\
\mathrm{N}=154\end{array}$} & \multicolumn{2}{|c|}{ Kruskal — Wallis test } \\
\hline & & & & $\mathrm{r}$ & $\mathrm{p}$ \\
\hline \multirow[t]{2}{*}{\begin{tabular}{|l|} 
Physical health \\
\end{tabular}} & $24,1(1,99)$ & $22,9(2,69)$ & & 3.05 & $0.006^{* *}$ \\
\hline & $24,1(1,99)$ & & $23,2(2,64)$ & 2,54 & $0.03^{*}$ \\
\hline \multirow[t]{2}{*}{ Psychological health } & $23,7(2,09)$ & $22,0(3,24)$ & & 4,21 & $0.000^{* *}$ \\
\hline & & & $22.2(2,75$ & 4,05 & $0.000^{* * *}$ \\
\hline \multirow[t]{2}{*}{ Social relationships } & $10,7(2,30)$ & $9,89(2,32)$ & & 2,39 & $0.03^{*}$ \\
\hline & 10,7 & & $9,98(2,40)$ & 2,24 & 0,07 \\
\hline \multirow{2}{*}{\begin{tabular}{|l|} 
Environment and \\
financial resources
\end{tabular}} & $32,4(3,91)$ & $29,3(4,60)$ & & 5,09 & $0.000^{* * *}$ \\
\hline & $32,4(3,91)$ & & $29,7(4,45)$ & 4,71 & $0,000^{* * *}$ \\
\hline \multirow{2}{*}{$\begin{array}{l}\text { The overall value of } \\
\text { quality of life }\end{array}$} & $91,0(8.18)$ & $84,1(11,1)$ & & 4,65 & $0,000^{* * *}$ \\
\hline & $91,0(8.18)$ & & $85,2(10,2)$ & 4,42 & $0.000^{* * *}$ \\
\hline
\end{tabular}

Table 10

Relationship between marital status and quality of life

\begin{tabular}{|l|l|l|l|l|l|}
\hline $\begin{array}{l}\text { Quality of life } \\
\text { indicators }\end{array}$ & $\begin{array}{l}\text { Married } \\
\mathrm{N}=182\end{array}$ & $\begin{array}{l}\text { Divorced } \\
\mathrm{N}=31\end{array}$ & $\begin{array}{l}\text { Lonely } \\
\mathrm{N}=12\end{array}$ & $\begin{array}{l}\text { Widowed } \\
\mathrm{N}=156\end{array}$ & $\mathrm{P}$ \\
\hline Physical health & $23.4(2.29)$ & $22.8(1.89)$ & $23.2(3.62)$ & $23.2(2,88)$ & 0.6 \\
\hline Psychological health & $22.5(2.65)$ & $22.9(2.66)$ & $23.0(4.12)$ & $22,3(3.10)$ & 0.7 \\
\hline Social relationships & $10.2(2.41)$ & $9.77(2.53)$ & $11.2(1.86)$ & $9.98(2.31)$ & 0.32 \\
\hline $\begin{array}{l}\text { Environment and } \\
\text { financial resources }\end{array}$ & $30.0(4.23)$ & $30.4(4.81)$ & $31.6(6.47)$ & $30.2(4.73)$ & 0.64 \\
\hline & $\begin{array}{l}\mathrm{p} \text { value was calculated using the Kruskal-Wallis test } \\
* \mathrm{P}<0.05 ; \\
* * \mathrm{P}<0.01 ; \\
\end{array}$ & & & \\
\hline
\end{tabular}


significantly lower quality of life indicators than patients without diseases. Table 8 depicts the differences between quality of life indicators and comorbidities.

As can be seen from Table 9, the quality of life as a whole was statistically significantly higher among respondents with higher education than among respondents with primary and secondary education. Whereas the quality of life of respondents with primary and secondary education did not differ.

When studying the quality of life depending on marital status (Table 10) we did not reveal statistically significant differences in the quality of life depending on marital status.

\section{Discussion}

In the present study, the psychometric properties of the developed Kazakh version of the WHOQOL-BREF questionnaire were tested in a pilot group of elderly patients selected from the total population of the Aktobe city. To avoid selection bias and reduce missing data, we used a personal interview as a survey. The reliability of the WHOQOL-BREF content was analyzed in a pilot group of 30 people (18 women, 12 men, with an average age of $67.3 \pm 5.03$ ). The results of the study showed satisfactory alpha coefficients in all areas of WHOQOL-BREF. The Alpha-Cronbach's coefficient was higher than 0,7 on all counts and showed a satisfactory level of internal consistency, which meets the necessary requirements [17]. Differentiation was highest in the physical and psychological domains, followed by the environmental domain, reaching a minimum in the social relationship domain. Compared with the results of the WHOQOL group of Iran [5], Germany [18], Turkey [9], in the Kazakh version, Cronbach's alpha coefficients of social relations were lower. One possible reason may be that after retirement, Kazakh elders are treated as a vulnerable population and are always cared for by their children instead of recruiting them for social activities. The results of other studies showed similar results, indicating the Cronbach's alpha coefficient of less than 0,7 in the field of social relationship [19]. Cronbach's small alpha coefficient in this area was probably also due to the fact that the area of social relations consists of only 3 questions; in addition, interpersonal relationships and sexual activity are relatively different concepts in the culture of the Kazakh-speaking elderly population.

The assessment of the reliability of the questionnaire in terms of the stability of the results over time was carried out by retesting the patients and calculating the Pearson correlation coefficient. The values of the Pearson correlation coefficient (r), when investigating the reliability of the instrument over time by re-testing, varied from $r=0,70$ to $r=0,78$, which indicates a high degree of correlation between the responses [20].

Thus, our pilot study showed that the high value of the coefficient of internal constancy $(\alpha=0,73)$ and the reproducibility results of the WHOQOL-BREF questionnaire $(r \geq 0,7)$ confirm the reliability of its Kazakh-language version. The developed Kazakh-language version of the WHOQOL-BREF questionnaire can be used by domestic scientists and doctors when planning and conducting clinical trials.

The results of the second part of our study showed that the study participants had a high level of quality of life $(85.0 \pm 10.5)$. There was no significant difference between the two sexes, however, women had a higher score than men $(\mathrm{P}=0.119)$. Moreover, there was a statistically significant difference in the assessment of the quality of life among women in the 4th domain "Environment and financial resources", demonstrating higher indicators than among men (29.5 (4.47) for men and 30.1 (4.57) for women, $\mathrm{p}=0.006$ ). Most likely, this fact is due to the fact that women at this age feel more mobile and free to move. Perhaps this is due to the fact that children have gained independence, there is a stable pension provision, a greater amount of free time that can be used for their own purposes. Also, children in many cases provide financial support to mothers, which is closely related to the mentality and upbringing in Kazakh society. Whereas men note lower indicators of the quality of life in this area. It can be assumed that this is most often associated with an increase in the number of chronic diseases and a decrease in the level of income in connection with retirement.

With regard to the effect of gender on quality of life, several studies have produced very different results. For example, in a study of domestic scientists who studied the quality of life of 236 elderly and senile respondents in the city of Nur-Sultan using the widespread questionnaire SF-36, men noted a higher standard of living [14]. At the same time, scientists noted that women have a more pronounced significant restriction of physical activity even when lifting a bag with food $-25.3 \%$ of elderly respondents and $34.8 \%$ of elderly respondents have significant restrictions. Accordingly, these same indicators are $13.8 \%$ and $27.8 \%$ among male respondents. A decrease in the stability of vitality in women was indicated by the fact that $20 \%$ of women were often very nervous, $27.2 \%$ of women often felt tired. For men, these numbers are $11.8 \%$ and $24.2 \%$, respectively. The opposite criterion, such as role functioning, the intensity of pain is noticeably higher in women than in men.

In a study by scientists from Iran, Yaser et al. who studied the quality of life and related factors of 184 elderly people living in Tabriz (Iran) did not reveal a significant difference in the indicators of the quality of life among men and women $(p=0.43)$, and there were no statistically significant differences separately by spheres. At the same time, the average indicators of the quality of life corresponded to an acceptable level [21]. Agreeing with this result, Ahmadi et al. [22] showed that there were no significant differences between sex and quality of life among 200 elderly people in the city of Zahedan aged 65 and over, according to the SF-36 quality of life questionnaire. It can be assumed that this is due to cultural beliefs and gender discrimination in the countries of the Muslim world. However, these findings have not been supported by studies conducted in Europe, where gender equality is one of the key criteria for the development of society.

In our study of the impact of education and marital status on quality of life, we found mixed results. When studying marital status, we did not reveal statistically significant differences both in individual areas and in the overall perception of the quality of life of the respondents, although in absolute terms the standard of living among single and unmarried individuals was slightly lower. While assessing the level of education and quality of life, it was found that the higher the level of education, the better the quality of life, which was confirmed by statistical data processing. Our data correlate with the results of similar studies in China. When studying the quality of life of the urban population in China in 1,052 adult respondents, of whom 192 $(18.3 \%)$ were over the age of 60 [23], the results showed that men had a significantly higher level of quality of life in the psychological field than women $(\mathrm{p}=0.05)$. While marital status is not related to quality of life, socioeconomic status, as measured by education and income, is largely related. Further analysis showed that, after controlling for other relevant variables, education has significantly more positive effects than income. Participants with a higher level of education had significantly 
higher physical, psychological, social and environmental factors of quality of life than those less educated. Inhabitants without chronic diseases, the physical quality of life was significantly higher than in residents with chronic diseases. In addition, employed persons have a significantly higher physical and social level of quality of life than unemployed persons.

In studies in Norway, which studied a random sample of the Norwegian population $(n=654)$ aged $18-75$ years using the WHOQOL-BREF questionnaire, 226 participants (36\%) of them elderly did not reveal statistically significant differences in the quality of life among the population by gender [24 ]. In a random sample of 1492 Dutch people aged 50 and over, [25] conducted a study to compare the relationship of gender, age, marital status, education and income with quality of life assessed by different questionnaires SF-12, WHOQOL-BREF and WHOQOL-OLD.

Higher age was associated with lower quality of life in 6 of the 12 quality of life domains. Being married or cohabitating, having a college degree, and having a higher income were associated with higher scores in 11, 10, and all 12 quality of life domains, respectively. However, the meaning of the influence of gender is completely different. In six areas of quality of life, women experienced significantly lower quality of life. Conversely, they experienced significantly better quality of life in three areas, all of which belong to the WHOQOL-OLD (sensory ability, autonomy and social participation). This questionnaire is more specific for conducting research on the quality of life among older people, which is a direction for further research in this area.

Younger age is associated with lower quality of life in rural areas of southern Brazil [26]. Brazilian people in the 60 to 69 age group rated their quality of life, as assessed by the WHOQOLBREF, lower in psychological and social relationships and overall quality of life. than people over 80. Soósová [27] showed that life without a partner is negatively associated with quality of life. On the other hand, using the same tool, Gobbens RJJ, van Assen M [28] demonstrated that marital status (married or living together) is associated only with the quality of intimacy in the domain of life, after controlling for other sociodemographic factors (age, education, and income).

More years of education were associated with higher scores in psychological, social relationships and environmental quality of life [29]. Additionally, in a study by Gobbens et al [30] higher education institutions are only significantly associated with improving the psychological and environmental quality of life. Soósová [27] observed a higher quality of life among older people with higher education.

However, this study had some limitations. The main limitation of this study was the small sample size of participants. In addition, we did not examine all the psychometric properties of the Kazakh-language version of the WHO questionnaire. Despite the assessment of some of the related factors affecting quality of life, the study of other factors was not possible in this study and may be proposed for future research.

\section{Conclusion}

This study demonstrates the good reliability and validity of the Kazakh language version of WHOQOL-BREF. Combined with the general scale, it can be used to contruct an evaluation system for measuring quality of life among older people.

This research is carried out only in the city of Aktobe. We then want to increase the sample size and conduct a multicenter study in Kazakhstan to assess its overall psychometric characteristics.

Disclosures: There is no conflict of interest for all authors.

Acknowledgements: None.

Funding: None.

\section{References}

1. Agency of the Republic of Kazakhstan on Statistics. Kazakhstan Demographic Yearbook 2019. Nur-Sultan, Kazakhstan: Agency of the Republic of Kazakhstan on Statistics. https://stat.gov.kz/edition/publication/collection.

2. Chu CY. Age-distribution dynamics and aging indexes. Demography. 1997; 34(4):551-63. https://doi.org/10.2307/3038309

3. The Ministry of National Economy of the Republic of Kazakhstan Statistics Committee and UNFPA. Population Situation Analysis of the Republic of Kazakhstan. May 2020. https://kazakhstan.unfpa.org/en/topics/population-matters-7.

4. Farzianpour, F., Hosseini, S., Rostami, M., Pordanjani, S. B. \& Hosseini, S. M. Quality of Life of the Elderly Residents. Am J of Appl Sci. 2012; 9(1):71-74. https://doi.org/10.3844/ajassp.2012.71.74.

5. Nejati V, Shirinbayan P, Akbari A, Foroughan M, Taheri P, Sheikhvatan M. Quality of life in elderly people in Kashan, Iran. Middle East J Age Ageing. 2008; 5(2):21-25. https://www.researchgate.net/publication/242459116

6. Ware JE Jr, Sherbourne CD. The MOS-36 item short-form health survey (SF-36) Med Care. 1992; 30(6):473-83. https://doi. org/10.1097/00005650-199206000-00002

7. Mellor D, Russo S, McCabe MP, Davison TE, George K. Depression training program for caregivers of elderly care recipients: implementation and qualitative evaluation. J Gerontol Nurs. 2008; 34(9):8-17. DOI: 10.3928/00989134-20080901-09

8. Gureje O, Ogunniyi A, Kola L, Afolabi E. Functional disability in elderly Nigerians: Results from the Ibadan study of aging. $J$ Am Geriatr Soc. 2006; 54(11):1784-9. DOI:10.1111/j.1532-5415.2006.00944.x

9. Donmez L, Gokkoca Z, Dedeoglu N. Disability, and its effects on quality of life among older people living in Antalya city center. Turkey Arch Gerontol Geriatr. 2005; 40(2):213-23. DOI: 10.1016/j.archger.2004.08.006

10. Bussche HV, Koller D, Olonko T, Hansen H, Wegscheide K. et al. Which chronic diseases and disease combinations are specific to multi morbidity in the elderly? Results of claims data based cross-sectional study in Germany. BMC Public Health. 2011; 11:101. DOI: $10.1186 / 1471-2458-11-101$

11. World Health Organization. Life in the 21st Century: a vision for all. Geneva, 1998. Available from: http:// www.who.int/whr/1998/en/ whr98_en.pdf.

12. The World Health Report 2000, Health Systems: Improving Performance, WHO, 2000. Available from: http:// www. who. int/ whr/ 2000/en/.

13. Lehnert T, Heider D, Leicht H, Heinrich S, Corrieri S. Review: health care utilization and costs of elderly persons with multiple chronic conditions. Med Care Res Rev. 2011; 68:387-420. DOI: 10.1177/1077558711399580 
14. G.R. Doszhanova, A.A. Abduldaeva, S.A. Iskakova. Assessment of the quality of life of elderly and senile people of the indigenous population of the city of Astana. Bulletin of KazNMU 2013, №2, p. 51-55. UDC:613.98-005.6(574.24)

15. Skevington SM, Lotfy M, O'Connell KA. The World Health Organization's WHOQOL-BREF quality of life assessment: psychometric properties and results of the international field trial A report from the WHOQOL group. Qual Life Res. 2004; 13(2):299-310. DOI: 10.1023/B:QURE.0000018486.91360.00

16. Burkovski G.V. Use of the WHO quality of life questionnaire in psychiatric practice/ G.V. Burkovsky, M.M. Kabanov, A.P. Kotsyubinsky E.V. Levchenko, A.S. Lomachenkov Psychosocial rehabilitation in psychiatry and neurology. Methodological and organizational aspects. - SPb.: -2017. - 600 c/ ISBN 978-5-299-00911-8

17. The World Health Organization's WHOQOL-BREF quality of life assessment: Psychometric properties and results of the international field trial. A Report from the WHOQOL Group. Quality of Life Research. 2004; 13(2):299-310. DOI:10.1023/B:QURE.0000018486.91360.00

18. Trompenaars FJ, Masthoff ED, Van Heck GL, Hodiamont PP, De Vries J. Content validity, construct validity, and reliability of the WHOQOL-Bref in a population of Dutch adult psychiatric outpatients. Qual Life Res. 2005; 14(1):151-60. DOI: 10.1007/s11136-0040787-X

19. Usefy A, Ghassemi GR, Sarrafzadegan N, Mallik S, Baghaei A, Rabiei K. Psychometric properties of the WHOQOL-BREF in an Iranian adult sample. Community Ment Health J. 2010; 46(2):139-147. DOI: 10.1007/s10597-009-9282-8

20. Lynn MR. Determination and quantification of content validity. Nurs Res. 1986; 35(6):382-6. https://doi.org/10.1097/00006199198611000-00017

21. Yaser Khaje-Bishak, Laleh Payahoo, , Bahram Pourghasem, and Mohammad Asghari Jafarabadi Assessing the Quality of Life in Elderly People and Related Factors in Tabriz, Iran. J Caring Sci. 2014; 3(4):257-263. doi: 10.5681/jcs.2014.028

22. Ahmadi F, Salar A, Faghihzadeh S. Assessing quality of life among elderly people in Zahedan. Hayat. 2004; 10(22):61-7.

23. Ping Xia,Ningxiu Li,corresponding author Kit-Tai Hau,Chaojie Liu, and Yubo Lu. Quality of life of Chinese urban community residents: a psychometric study of the mainland Chinese version of the WHOQOL-BREF. BMC Med Res Methodol. 2012; 12:37. doi: 10.1186/1471-2288-12-37

24. Mary H. Kalfoss,1 Randi J. Reidunsdatter,2 Christian A. Klöckner,3 and Marianne Nilsen. Validation of the WHOQOL-Bref: psychometric properties and normative data for the Norwegian general populationHealth Qual Life Outcomes. 2021; 19:13. doi: 10.1186/ s12955-020-01656-X

25. Robbert JJ Gobbens and Roy Remmen. The effects of sociodemographic factors on quality of life among people aged 50 years or older are not unequivocal: comparing SF-12, WHOQOL-BREF, and WHOQOL-OLD. Clin Interv Aging. 2019; 14:231-239. doi: 10.2147/ CIA.S189560

26. Gambin G, Molzahn A, Fuhrmann AC, Morais EP, Paskulin LM. Quality of life of older adults in rural southern Brazil. Rural Remote Health. 2015; 15(3):3300. https://doi.org/10.22605/RRH3300

27. Soósová MS. Determinants of quality of life in elderly. Central Euro J Nurs Midwifery. 2016; 7(3):484-493. https://doi. org/10.15452/ CEJNM.2016.07.0019

28. Gobbens RJJ, van Assen M. Associations between multidimensional frailty and quality of life among Dutch older people. Arch Gerontol Geriatr. 2017; 73:69-76. https://doi.org/10.1016/j.archger.2017.07.007

29. Gambin G, Molzahn A, Fuhrmann AC, Morais EP, Paskulin LM. Quality of life of older adults in rural southern Brazil. Rural Remote Health. 2015; 15(3):3300. https://doi.org/10.22605/RRH3300

30. Gobbens RJ, Luijkx KG, van Assen MA.Explaining quality of life of older people in the Netherlands using a multidimensional assessment of frailty. Qual Life Res. 2013; 22(8):2051-61. https://doi.org/10.1007/s11136-012-0341-1 